\title{
A Família Homoparental na Ficção Televisiva: As Práticas Narrativas do Brasil e da Espanha como Relatos das Novas Representações Afetivo-Amorosas*
}

\author{
Aline Martins Mesquita ${ }^{1}$ \\ Carme Ferré Pavia ${ }^{2}$ \\ ${ }^{1}$ Universitat Autònoma de Barcelona (UAB), Barcelona, Espanha. E-mail: \\ alinemartinsm@gmail.com. \\ 22Universitat Autònoma de Barcelona (UAB),Barcelona, Espanha. E-mail: carme.ferre@uab.cat.
}

\section{INTRODUÇÃO}

T a sociedade atual, novas formas de relacionamentos, novos con1 tratos e novos códigos, entre outros aspectos, implicam distintas representações afetivo-amorosas entre os casais. Estes frutos da contemporaneidade têm profunda relação com a transformação da intimidade pessoal, com a evolução que Giddens denomina "sexualidade plástica" (2004:12), liberada de sua relação com a reprodução, orientada à negociação sexual.

Segundo Roudinesco (2003), a mudança contribuiu para uma outra forma de enxergar as relações afetivo-amorosas e gerou uma grande "desordem", vivenciada pela nova organização social-a família. Aautora observa que, desta forma, "a transmissão da autoridade é cada vez mais problemática, à medida que divórcios, separações e recomposições conjugais aumentam" (ibidem:19). A autora parafraseia JeanJacques Rousseau ao evidenciar a relevância da família como a mais antiga de todas as sociedades, e a única natural.

Atualmente, a questão sobre a constituição do parentesco e da família vem se redefinindo, começando pelas margens da sociedade ou por si-

\footnotetext{
* Este artigo surgiu da pesquisa de doutorado de Aline Martins Mesquita, defendida em julho de 2012, na Universitat Autònoma de Barcelona (Espanha), sob a orientação de Carme Ferré Pavia.

DADOS - Revista de Ciências Sociais, Rio de Janeiro, vol. 58, nn-1, 2015, pp. 223 a 255.
} 
tuações especiais. Sabemos disto porque, frequentemente, as ideias, as condutas, muitas vezes passíveis de discriminação, movimentam-se para o centro por intermédio da cultura popular, e durante este processo esta pode transformar-se em uma força e um espelho da mudança social. Podemos afirmar, neste sentido, que, na televisão, as novelas e as séries de ficção, de forma geral, se converteram, pelo que o parentesco se refere, em um popular terreno de jogo da mudança cultural (Martín-Barbero, 2002). Na perspectiva do grupo de pesquisa das autoras, a comunicação tem na pluralidade e no equilíbrio de representação das minorias uma responsabilidade social como ferramenta de socialização cidadã.

Em nenhum momento na história têm sido tão visibilizados publicamente na televisão o protagonismo feminino, o enfraquecimento da família convencional, o aparecimento de novas formas de convivência, mediante diferentes estilos ou modelos de vida e novas performances de gênero, sendo as tramas das séries de televisão as principais mediações para representar ou recriar estes acontecimentos, potencializando o cotidiano das pessoas.

Tomamos como exemplo nosso objeto de estudo, a família homoparental $^{1}$ - ou família homoafetiva - na ficção televisiva. Embora ainda consideremos sua incidência pontual, nas tramas televisivas de forma geral, na perspectiva do tratamento aprofundado das representações afetivo-amorosas e de seus aspectos correlacionados como paternidade/maternidade e educação de filhos, admitimos que este tipo de relato já vem sendo discutido nos programas televisivos e ganha cada vez mais força no espaço midiático. Por este motivo, fomentamos o interesse em promover uma reflexão acerca das possíveis mudanças nos valores e representações de gênero e sexualidade, a partir da imagem da família homoparental, apresentada tanto na série de ficção espanhola Hospital Central ${ }^{2}$ (Telecinco, 2000-2012) quanto na novela brasileira Páginas da Vida ${ }^{3}$ (Rede Globo, 2006-2007).

De forma resumida, reforçamos que uma série de ficção apresenta caráter autoconclusivo dos seus episódios, em que o grau de serialização entre eles é mínimo ou inexistente. Como argumenta García de Castro (2002), a trama costuma centrar-se na resolução do caso de cada um dos episódios, orientando-se mais à ação. As séries de tipo criminal, mistério, policial ou hospitalar são exemplos deste formato narrativo. No caso da telenovela, tradicionalmente melodramática, especifica- 
mente a produzida na América do Sul, La Pastina, Rego e Straubhaar (2004) reforçam que se trata de uma obra vitrine da burguesia, com mais de 100 capítulos interdependentes, mitigando as aspirações não alcançadas do telespectador. Por serem produções de ficção, assemelham-se na apresentação de dramas crítico-realistas, mobilizando a opinião pública à mudança social.

Além do fato de Hospital Central ser uma série de ficção espanhola de grande duração, esta produção nos chama a atenção pela abordagem de uma relação homossexual formada por duas mulheres que trabalham no hospital, que almejam ter filhos e que contraem matrimônio diante de um juiz; este fato foi exibido em 2005, ano em que a Espanha começou a reconhecer, legalmente, o casamento entre pessoas do mesmo sexo. Seguindo este recorte cronológico, buscamos na novela Páginas da Vida, através do casal formado por dois homens, um interessante caso de inserção de uma família homoparental estável na televisão brasileira que também acompanhou as mudanças no terreno amoroso. Por tal razão, esta novela complementa nosso universo de pesquisa pelo seu pioneirismo na abordagem, ainda que simbolicamente aprofundada, na televisão aberta do Brasil.

Cabe acrescentar que a homoparentalidade, de progenitores do mesmo sexo, é um tema que avança em investigações das áreas da sociologia, psicologia, antropologia e serviço social (Flaquer, 1991; Perelson, 2006; Medeiros, 2006; Reyes, 2007; Fonseca, 2008; Robaldo, 2011; Ceballos Fernández, 2012). Este tipo de estudo está sendo potencializado graças aos avanços nos direitos dos homossexuais; no entanto, não o encontramos no âmbito da comunicação. Portanto, o presente artigo pode ajudar a criar referências que até o momento não existem.

\section{MARCO TEÓRICO-REFERENCIAL: A RELEITURA DA CONVIVÊNCIA}

Diversos autores afirmam que a instituição familiar se tornou um fenômeno complexo pelos seus variados arranjos estruturais, consequência de importantes mudanças em normas sociais e sexuais (Castells, 1999; Roudinesco, 2003; Giddens, 2004). Essas mudanças desafiaram a família tradicional e nuclear, formada por pai, mãe e filhos. O século XVIII foi marcado pelo surgimento do feminismo, que "com o advento da burguesia, transformou a família em uma célula biológica que concedia lugar central à maternidade". Uma nova ordem familiar apareceu, "permitindo às mulheres reafirmarem sua diferença, aos filhos 
serem olhados como sujeitos e, aos 'invertidos' ${ }^{4}$, se normalizarem" (Roudinesco, 2003:11).

Nessa direção, torna-se imprescindível abordar a estrutura mais básica de todas as sociedades contemporâneas: o patriarcado. Como verificamos em Castells (1999), o patriarcado se caracterizou pela autoridade e poder dos homens sobre as mulheres e seus filhos na unidade familiar. A repercussão dos movimentos sociais, sobretudo do feminismo nas relações de gênero, desencadeou uma onda expansiva: foi posta nas entrelinhas a heterossexualidade como norma.

Já para os homossexuais masculinos, o questionamento da família tradicional e as relações conflituosas entre homens e mulheres representaram "[...] una oportunidad para explorar otras formas de relaciones interpersonales, incluídas nuevas formas de familia, las familias gays" (Castells, 1999:162). O autor complementa que a liberação sexual sem limites institucionais se converteu em uma nova fronteira da expressão pessoal, sem vínculos com a imagem homofóbica promíscua, mas, da afirmação do eu, e na experimentação com a sexualidade e o amor. Para ele, a debilitação da família patriarcal foi observada na década de 1990, sobretudo nos países mais desenvolvidos. Um primeiro indicador do desapego a um modelo de família que estava baseado no compromisso, a longo prazo, dos seus membros, foi a desintegração dos casais, através do divórcio ou da separação, um processo em que o desejo se encarna na vontade (Bauman, 2007).

\section{A Família Homoparental}

A transformação das formas de encarar o amor, a sexualidade e a reprodução, vem atingindo a todos, independentemente de orientação sexual. Foucault (1984) reforça a dificuldade secular, em nossa sociedade, em integrar os dois fenômenos: a inversão dos papéis sexuais e a relação entre indivíduos do mesmo sexo. Encontramos uma noção pertinente para ilustrar a família homoparental, no que se refere às "famílias que escolhemos" (Fonseca, 2008), ligada aos novos arranjos familiares.

Giddens argumenta que algumas sociedades possuem uma história maior de tolerância sexual que outras, e que as mudanças que experimentam não são, às vezes, tão radicais quanto em países como os Estados Unidos, por exemplo. O autor recorre à Alfred Kinsey ${ }^{5}$ (1948 apud Giddens, 2004:22; 1953) - já que suas pesquisas sobre a sexualidade hu- 
mana influenciaram profundamente os valores sociais e culturais dos Estados Unidos, principalmente na década de 1960, com o início da revolução sexual - para ilustrar o que foi um possível indício deste radicalismo: seu relatório revelou que apenas $50 \%$ de todos os homens americanos eram "exclusivamente heterossexuais"; $18 \%$ deles eram ou exclusivamente homossexuais, ou persistentemente bissexuais; $13 \%$ haviam participado de alguma forma de atividade homossexual, enquanto que mais de $15 \%$ confessaram que haviam tido desejos homossexuais sem haver cedido a eles.

Giddens (ibidem) recorda que, inclusive na época em que apareceram os livros de Kinsey, a homossexualidade ainda era vista como uma patologia, um transtorno psicossexual. Igualmente, não devemos perder de vista o fato de que as sociedades buscam - quando há interesse político - tolerar a existência dos homossexuais e, também, suas uniões, dentro do campo jurídico; no entanto, limitaram-lhes os direitos que já vinham sendo aplicados aos heterossexuais (Pérez Cánovas, 1996; Villaamil, 2004). Isto porque, na visão de Mira (2007), a resistência à normalização não se produzia na forma de modelos alternativos ao ativismo, mas, defensiva ou negligente. Apesar disso, cada uma das conquistas, ainda que em proporções limitadas, constituiu um passo decisivo na tarefa pendente de acabar com uma situação discriminatória.

Os exemplos de conquistas do coletivo homossexual, que pareciam restritos ao contexto europeu, são realidade no continente americano da América do Norte à América do Sul. As regras que valem para relações estáveis entre homens e mulheres, aplicadas aos casais gays, já não afetam apenas os casais homossexuais de países como Holanda, Bélgica, Espanha, Suécia ou Islândia. Estados norte-americanos, México, Argentina e, recentemente, Brasil, já reconhecem a união estável entre casais do mesmo sexo como entidade familiar. No entanto, cabe trazer à luz um pertinente pensamento de Belgrano Rawson (2012), que chama a atenção para a importância do reconhecimento legal dos casais de mesmo sexo, aliado às medidas similares impulsionadas por uma democracia motivada pelo que denomina "cidadania sexual" 6 .

\section{A Nova Família na TV: Brasil e Espanha}

Segundo o Censo Demográfico 2010, do Instituto Brasileiro de Geografia e Estatística (IBGE) ${ }^{7}$, o Brasil tinha mais de 60 mil casais homossexuais, que, a partir de maio de 2011, já poderiam ter direitos garantidos 
como herança, comunhão parcial de bens, pensão alimentícia e previdenciária, licença médica ou inclusão do companheiro como dependente em planos de saúde. A sentença do Superior Tribunal Federal foi um marco importante na história legislativa do país, um dos mais homofóbicos do mundo ${ }^{8}$, uma vez que há mais de 15 anos o coletivo homossexual esperava pela aprovação de um projeto menos complexo, o de Parceria Civil Registrada que, devido à polêmica, não era colocado em votação pelos senadores federais. Esse projeto, criado em 1995, não tinha pretensões de equiparar as uniões homossexuais com os casamentos convencionais; por esta razão, a palavra casamento nunca foi utilizada no projeto e, mesmo assim, não foi debatido amplamente, devido a resistências diversas, sobretudo da sociedade civil e dos operadores do direito.

Antes da aprovação da união homossexual no Brasil, os casais homossexuais só podiam firmar contratos de união estável. Com a decisão da Justiça, está permitida também a adoção de filhos, o que divide ainda mais as opiniões. No entanto, os casamentos de caráter civil entre pessoas do mesmo sexo não param de acontecer, inclusive em estados menos desenvolvidos da federação. $\mathrm{O}$ tamanho da discriminação foi traduzido em números pelo Instituto Brasileiro de Opinião Pública e Estatística (Ibope), em pesquisa realizada em julho de 2011. De acordo com o órgão, 55\% da população brasileira não aprovava a união entre pessoas do mesmo sexo 9 . A pesquisa revelou, ainda, que o percentual era o mesmo quando se tratava da adoção de crianças por casais homossexuais: $55 \%$ dos brasileiros eram contrários e $45 \%$ a favor. O levantamento trouxe à tona que, "nos dois casos, a resistência é maior entre os homens, os evangélicos, os mais velhos, pessoas com menos escolaridade e de classes mais baixas. Nessas categorias, os índices de rejeição às causas homossexuais são maiores". Uma sociedade marcada por desigualdades capazes de promover desarmonias de poder social e oportunidades de vida é notadamente menos tolerante (Santos, 2011).

No caso espanhol, a aprovação da lei do casamento homossexual, em 2005, motivou conflitos envolvendo a população, a Igreja Católica e o partido opositor, o PP (Partido Popular). Mais de 8.700 casamentos gays foram celebrados na Espanha até 2008, conforme estudo realizado pelo Instituto Nacional de Estadística ${ }^{10}$.

O número nos chama a atenção para a ânsia da adoção da ordem familiar que, como bem sabemos, chegou a contribuir para a desventura do 
coletivo homossexual. Essa aproximação da instituição familiar é um traço marcante de uma relação afetiva, construída na ausência de uma lei consensual. Em outras palavras, a inexistência de normas fixas transformaria a família homoparental em uma instituição carente de regras comuns.

Na televisão dos dois países, a nova família ganhou destaque paralelamente às conquistas do coletivo homossexual. Em 2005, o reconhecimento da lei do casamento homossexual, na Espanha, incidiu quase que imediatamente no argumento narrativo da série Hospital Central, na qual os personagens Maca e Esther oficializaram a união diante de um juiz, na trama fictícia. O casal protagonizou debates sobre maternidade, inseminação artificial, educação de filhos e até batizado. Foi uma prática narrativa consistente e reveladora da experiência homossexual como não se havia apreciado com tal profundidade anteriormente na televisão espanhola, apesar das inúmeras inserções de personagens homossexuais na ficção, especialmente desde os anos 1980, quando novas e transgressoras representações, inclusive da mulher, começaram a aparecer (Sáez Mateu, 2008).

No final da década de 1990 os personagens homossexuais começaram a atuar com "normalidade", o que, segundo o autor, significava que a homossexualidade era somente um componente a mais do personagem, não o que lhe definia de forma unidimensional. Para nossa pesquisa, o conceito de normalidade em uma obra narrativa é pertinente, também, por relacionar-se à representação familiar vinculada à figura homossexual, não apenas demarcando sua presença individual na trama.

A partir do ano 2000, algumas séries trataram de apresentar, ainda que de maneira estereotipada, personagens regulares, com narrativa enfocada em sua homossexualidade, como aconteceu em Siete Vidas (Telecinco, 1999-2006), El Cor de la Ciutat (TV3, 2000-2009), Jet Lag (TV3, 2001-2006) ou Aquí no Hay Quien Viva (Antena 3, 2003-2006).

O imediatismo da tradução da vida real em ficção também aconteceu no Brasil. Não obstante, cabe rememorar que as representações iniciais da homossexualidade costumavam se centrar na orientação sexual dos personagens. Nos programas humorísticos da televisão brasileira, por exemplo, a imagem do homossexual efeminado era a mais comum desde os anos 1970 (Nunan, 2003). A imagem estereotipada começou a

DADOS - Revista de Ciências Sociais, Rio de Janeiro, vol. 58, nº 1, 2015 
perder força a partir da década de 1980, com personagens secundários em novelas da emissora Rede Globo, como Vale Tudo (Rede Globo, 1988-1989 - com um casal de lésbicas); A Próxima Vítima (Rede Globo, 1995 - com o jovem casal homossexual masculino); Por Amor (Rede Globo, 1997-1998 - na qual um bissexual abandona sua mulher e filho para viver um romance homossexual); Torre de Babel (Rede Globo, 1998-1999 - com um casal de lésbicas maduras); Mulheres Apaixonadas (Rede Globo, 2003 - em que um casal lésbico trocou carícias explícitas) ou mesmo Senhora do Destino (Rede Globo, 2004-2005 - na qual duas jovens se apaixonaram e adotaram um recém-nascido). Vale destacar que esses personagens não formavam uma união estável e, naquele momento, causaram bastante polêmica na sociedade, sendo minimizados nas tramas ou mesmo excluídos da narrativa, como aconteceu com o casal de lésbicas de Torre de Babel, que morreu em uma explosão em um centro comercial, depois de sua repercussão negativa.

Apesar do avanço dramático que as representações homossexuais produziram na sociedade, cabe enfatizar que a profundidade na abordagem homoparental não recebeu muito destaque no Brasil. Como argumenta Joyce (2013), a progressiva representação homossexual na televisão brasileira vinha sendo limitada em um importante aspecto: a ausência de um beijo entre os casais gays. Demorou, mas aconteceu.

No mesmo mês em que o Judiciário brasileiro aprovou o casamento homossexual e a segurança jurídica que isso implica para as famílias gays, a televisão deste país mostrou uma cena histórica: um beijo entre duas mulheres. Em 12 de maio de 2011, os telespectadores do canal SBT ${ }^{11}$ assistiram ao beijo entre Marina e Marcela, personagens da novela Amor e Revolução (SBT, 2011-2012). Esta obra de ficção foi a primeira a conceber e a transmitir uma cena do beijo gay - já mitificado na televisão brasileira - sem interferências. Em 2005, o setor de dramaturgia da emissora Rede Globo escreveu uma cena de beijo homossexual para a novela América, que acabou vetado pela emissora. Naquela época, a Rede Globo justificou o veto, com base nos "Princípios de Qualidade da TV Globo", que não contemplariam "beijos gays e carícias".

A repercussão foi grande após a atuação das atrizes da novela Amor e Revolução, de forma que o autor, Tiago Santiago, condicionou a continuação do romance das duas à aceitação do público ${ }^{12}$. A resposta positiva encorajou o autor a escrever outra cena de beijo gay, desta vez entre 
dois homens na novela, o que não aconteceu porque a emissora estava preocupada com a audiência mais conservadora.

O mítico beijo gay, uma vez vetado pela Rede Globo, finalmente foi levado ao ar em uma telenovela da emissora. Em Amor à Vida (Rede Globo, 2013-2014), o beijo ${ }^{13}$ entre os personagens Félix e Niko, no último capítulo da novela, foi considerado o mais esperado pelo país, respondendo a uma necessidade dramatúrgica e, sobretudo, refletindo o momento que vive a sociedade brasileira.

\section{DESENHO METODOLÓGICO}

Os pressupostos teóricos e metodológicos que fundamentam esta investigação, de caráter qualitativo, buscam elementos da narratologia a teoria dos textos narrativos - para analisar os aspectos de interesse desse texto televisivo empírico, do ponto de vista do seu conteúdo. De acordo com Bal (1990), um texto narrativo é composto pelo texto em si, por uma história e uma fábula. Caberá a esta pesquisa deter-se ao texto narrado da série Hospital Central e da novela Páginas da Vida, com seus acontecimentos relacionados aos personagens selecionados, representativos de unidades semânticas completas. Nessa perspectiva, estudaremos o que concerne ao o que é dito no texto, e não como é dito. Faremos, ainda, um breve estudo de recepção para entender como os coletivos homossexuais dos dois países percebem as obras de ficção abordadas aqui e os contextos televisivos nos quais estão inseridos.

\section{Objetivos}

Neste estudo, pretendemos alcançar os seguintes objetivos específicos:

a) Descrever como a televisão, através das séries de ficção e das novelas, atua em um mundo construído a partir da realidade, analisando os valores afetivo-amorosos que transmite;

b) Investigar a inserção e o tratamento de duas famílias homoparentais - uma presente na trama da série espanhola Hospital Central e outra na novela brasileira Páginas da Vida -, a fim de identificar as diferenças nas relações afetivo-amorosas dos personagens e seus vínculos paterno-filiais;

c) Averiguar o impacto das produções examinadas, através de uma análise virtual-comparativa para Espanha e Brasil;

DADOS - Revista de Ciências Sociais, Rio de Janeiro, vol. 58, no 1, 2015 
d) Oferecer elementos teórico-metodológicos para a criação de um campo de estudo acadêmico que investigue a família homoparental na ficção televisiva.

\section{Amostras e Modelo de Análise de Conteúdo}

A classificação da série de ficção Hospital Central e da novela Páginas da Vida, como amostras da análise, foi realizada a partir da articulação entre gênero (drama), presença regular de uma família homoparental (relação estável), e protagonismo (personagens fixos na amostra selecionada). A partir do exercício empírico de visualização de capítulos das duas obras de ficção, pretende-se encontrar dados qualitativos sobre o tratamento que se dá à família homoparental na ficção televisiva, valendo-nos de uma perspectiva comparativa ligada às particularidades deste tipo de família, formada por duas mulheres, Maca e Esther (família homoparental 1) e outra, formada por dois homens, Marcelo e Rubinho (família homoparental 2).

Em termos mais formais, esta pesquisa foi concebida após observação empírica de 197 capítulos, referentes às duas obras audiovisuais, divididos em: 28 capítulos de Hospital Central (temporadas 9/10 = 25 capítulos; temporadas $11,12,13=3$ capítulos) e 169 capítulos de Páginas da Vida, o que, cronologicamente, totaliza mais de 10 mil minutos analisados. Além disso, com base na percepção de Casetti e di Chio (1999:240), desenvolvemos a análise de conteúdo das obras a partir de um recorte predeterminado, tendo em conta, nos capítulos estudados, os fenômenos de interesse, identificados após observação e selecionados em forma de sequências de interesse, numeradas de 1 a 228, de modo a facilitar a localização das referências na análise, e com sua minutagem final, quando se tratar, especificamente, dos casais estudados.

Como esta análise constitui o enfoque mais tradicional do texto, partiremos do princípio de que estes programas televisivos, além de corresponder a um instrumento de transmissão de representações, são, ainda, realizações linguísticas e comunicativas nas quais nos interessam seus códigos verbais e as manifestações evidentes e específicas de cada fator estudado: personagens, ações e transformações.

Nos Quadros 1 e 2, apresentamos uma mostra das sequências de interesse da pesquisa, e, em seguida, os dados adicionais da análise realizada das obras de ficção e informações gerais sobre cada uma: 
A Família Homoparental na Ficção Televisiva...

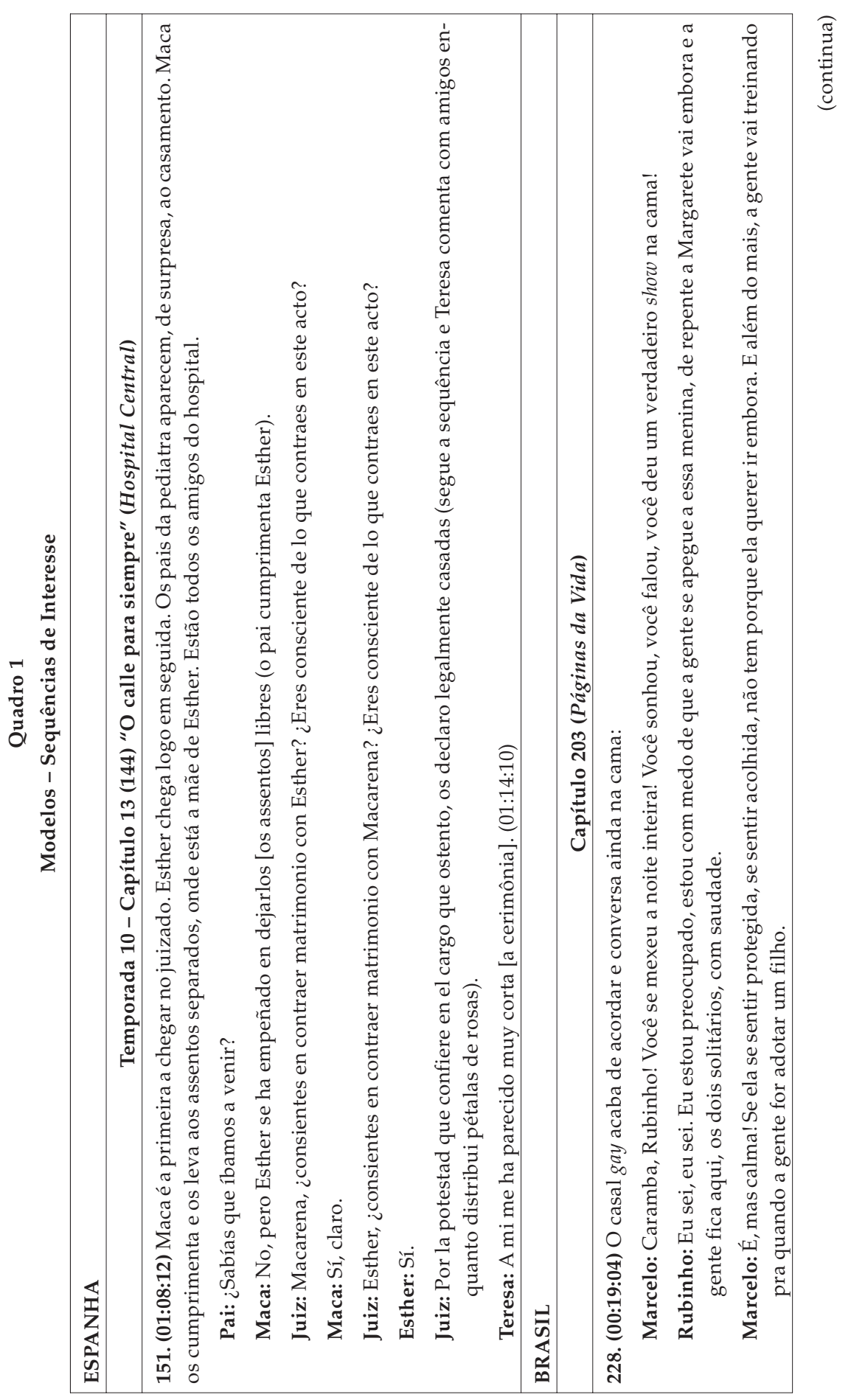

DADOS - Revista de Ciências Sociais, Rio de Janeiro, vol. 58, nํㅜ 1, 2015 


\section{Aline Martins Mesquita e Carme Ferré Pavia}

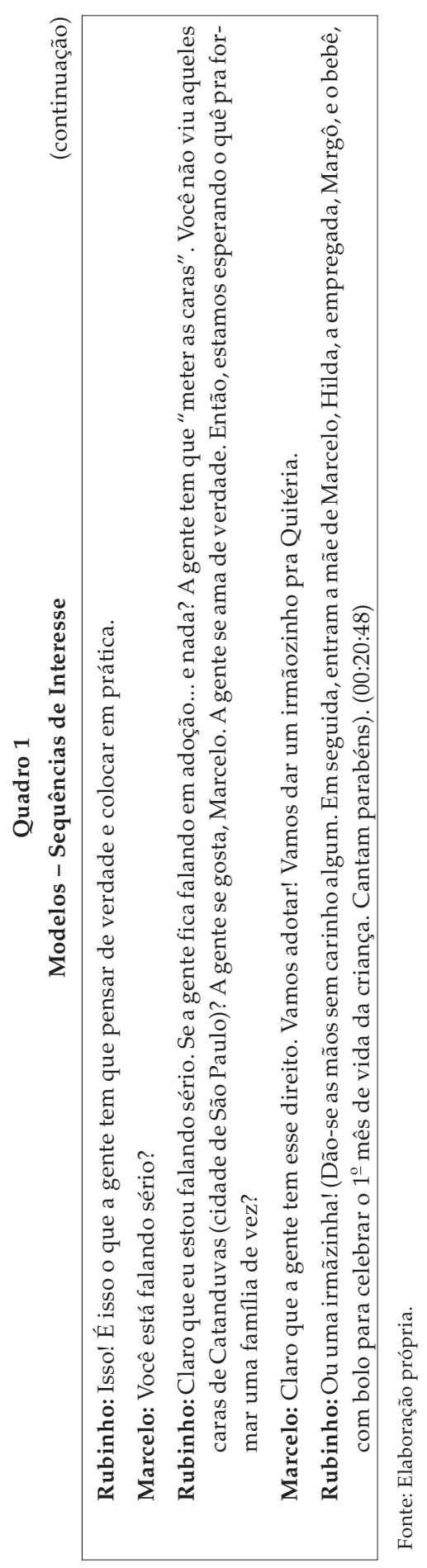

234 DADOS - Revista de Ciências Sociais, Rio de Janeiro, vol. 58, no 1, 2015 
A Família Homoparental na Ficção Televisiva...

Quadro 2

Especificidades - Hospital Central e Páginas da Vida

\begin{tabular}{|l|c|c|}
\cline { 2 - 3 } \multicolumn{1}{c|}{} & Hospital Central & Páginas da Vida \\
\hline País & Espanha & Brasil \\
\hline Emissor & Telecinco & Rede Globo \\
\hline Início de emissão & 2000 & 2006 \\
\hline Final de emissão & 2012 & 2007 \\
\hline Gênero & Série de ficção & Novela \\
\hline Microgênero & Drama hospitalar & Melodrama \\
\hline Horário & Prime time & Prime time \\
\hline Periodicidade & Semanal & Diária \\
\hline Duração/capítulo & $70^{\prime}$ & $40^{\prime}$ \\
\hline Sequências de interesse & 165 & 63 \\
\hline Capítulos estudados & 28 & 203 \\
\hline Temporadas estudadas & $9-13$ & - \\
\hline Tempo estudado (minutos) & 2.080 & 8.120 \\
\hline Casal homossexual & Maca e Esther & Marcelo e Rubinho \\
\hline
\end{tabular}

Fonte: Elaboração própria.

Recorremos a Igartua et al. (1998) para apreendermos os aspectos mais relevantes dos personagens, objetos de nossa investigação, no que se refere aos atributos morfológicos (descrição física e características corporais) e aos atributos funcionais (aspectos psicológicos ou traços de personalidade, comportamentos e temas), apresentados pelos personagens da narrativa seriada. Outros trabalhos destacaram o estudo do caráter e as atribuições aos personagens, como forma de analisar a representação do coletivo (Fouts e Inch, 2005).

Para este artigo, os dois atributos serão tomados em consideração porque apresentam dados importantes para a análise dos perfis sociais, abordados na série estudada. Além disso, acrescentaremos à investigação os atributos narrativos, relacionados aos aspectos próprios da narração televisiva, como presença na tela. Desta forma, respeitaremos as abreviações utilizadas para a ficha referencial da nossa análise:

- AM - Atributos morfológicos (dos personagens);

- AF-Atributos funcionais (dos personagens, temas e seu ambiente);

- AN - Atributos narrativos (da presença dos personagens na tela).

DADOS - Revista de Ciências Sociais, Rio de Janeiro, vol. 58, nº 1, 2015 
A elaboração das categorias para a análise textual obedece à seguinte lógica:

Estabelecimento de categorias gerais e metodológicas para a análise, como:

- Casal homossexual 1 (Maca e Esther);

- Casal homossexual 2 (Marcelo e Rubinho);

- Relação amorosa tradicional (representativa de normas sociais dominantes);

- Relação amorosa não tradicional (não representativa de normas sociais dominantes);

- Qualificações dos personagens e de suas relações;

- Temas abordados pelos casais;

- Conflitos entre o casal e a relação paterno-filial.

A partir da definição dos critérios de interesse, elaboramos a nossa análise textual, obedecendo a uma lógica que estabelece como critérios as características corporais ou rasgos de personalidade (comportamentos) comuns dos personagens. É esta estereotipização dos personagens em torno de uma série limitada de traços que facilitam um rápido reconhecimento pelas audiências (Montero Rivera, 2005). Esta parte do estudo considerará, então, os principais protótipos encontrados nas tramas narrativas de ficção (Igartua et al., 1998). A caracterização psicológica, por exemplo, compreenderá traços de maior incidência na televisão, como personagens com personalidade sociável, passiva, poderosa, agressiva, ciumenta ou responsável. Para nosso estudo, acrescentaremos à lista, valores morais, temperamento, aptidões, atitudes e qualidades de ser introvertido ou extrovertido. No tocante às emoções, utilizaremos quatro básicas (Galán e Herrero, 2011; Igartua et al., 1998): alegria, medo, raiva e tristeza.

Partindo destes atributos, utilizaremos outros traços funcionais (psicológicos) que complementarão nossa lista, ligados a estados, disposições e aspectos sociais (Iraegui e Quevedo, 2002). Exemplos destes traços podem ser: dialogante, respeituoso, generoso, amável, elegante, sério, nervoso, inteligente, decidido ou sedutor.

Quando os atributos se relacionarem a temas ligados aos casais analisados, teremos em mente que, como em toda narração, este repertório temático deverá estar conectado a um conflito que os personagens te- 
rão de enfrentar. Como afirmaram Galán e Herrero, "[...] las buenas historias provienen de grandes conflictos: el miedo, el amor, la soledad, los secretos, los deseos inalcanzados... Cuanto más universal sea este conflicto, más fácil será la identificación con el público" (2011:95).

Assim, os conflitos que serão selecionados para nosso trabalho serão baseados nestes de caráter universal, além dos que classificaremos de acordo com os contextos relacionados de cada obra que compõe a investigação, considerando, ainda, suas características sociais, como classe, educação, ócio, vida familiar, cultural e profissional. Com todas estas características definidas, reunimos nossos principais elementos referenciais metodológicos, considerados após observação empírica.

\section{DESENHO DA ANÁLISE VIRTUAL-COMPARATIVA}

Nesta parte, centramo-nos na importância de conhecer as opiniões de audiências específicas que, em princípio, estariam mais comprometidas com a causa homossexual dos dois países estudados. Estas audiências se transformariam em um recurso valioso para conhecer o universo que compõe o contexto aqui analisado e para aprender o que os informantes pensam sobre um fenômeno de interesse.

Reiteramos, então, que a assistência dos entrevistados se produziu a partir de uma demanda da investigação e que a análise de respostas teve um caráter ideológico. Este enfoque quantitativo-qualitativo, portanto, obedeceria ao que preconizaram Hernández Sampieri et al. (2003), referente ao caráter não probabilístico do universo entrevistado, já que a eleição dos elementos da mostra seguiria critérios convenientes para a investigação.

\section{Os Grupos}

Objetivamos a participação, através de seus membros associados, de duas entidades militantes, do ponto de vista reinvidicativo da causa homossexual. Buscamos organizações relevantes para seu contexto e de expressividade comprovada na luta pela normalização da homossexualidade nas sociedades em que atuam. Seguimos, então, com a parceria com o Grupo Gay da Bahia ${ }^{14}$, iniciada em 2008. A entidade espanhola foi escolhida com base na sua especificidade: uma associação de famílias LGBT (Lésbicas, Gays, Bissexuais, Travestis, Transexuais e Transgêneros), localizada em Barcelona. A Associació de Families Lesbianes i Gais ${ }^{15}$ se mostrou solícita, animando seus membros a parti- 
ciparem da pesquisa e responder ao questionário. Nos dois grupos, o contato estabelecido aconteceu mediante a direção das entidades, o que, a nosso ver, representou mais facilidade na sensibilização dos informantes.

Tivemos o interesse em procurar ao máximo traçar o perfil dos entrevistados, de modo a compreender melhor a composição de cada entrevistado e o que os diferenciava. Este entendimento cultural e até mesmo simbólico das características dos grupos poderia, em nossa opinião, ser um elemento de grande valor, já que enriqueceria os critérios de orientação nas análises qualitativas (Serbia, 2007). Assim, definimos como fatores de interesse referentes aos participantes: nome, profissão/ocupação e entidade a que pertenciam. Este último se referia à necessidade de comprovar a origem dos informantes, porque consideramos a possibilidade de os questionários ultrapassarem as barreiras das entidades contatadas.

\section{Uma Web Bilíngue ${ }^{16}$}

O conteúdo do trabalho apresentado na web foi desenvolvido em questionários estruturados em dois idiomas, dependendo da escolha do respondente, brasileiro ou espanhol: português ou castelhano. Para cada contexto, um fragmento da novela e da série estudadas que consideramos relevante para caracterizar as duas relações homoafetivas. A sequência de Hospital Central foi a que representou um ineditismo na televisão espanhola, a do casamento entre duas mulheres (Seq. 228/cap. 203/00:19:04). Já no caso de Páginas da Vida, selecionamos a cena do último capítulo da novela, que contempla a decisão do casal homossexual, em sua cama, de adotar uma criança (Seq. 151/cap. 13/01:08:12). Assim, após a visualização de cada cena, nos contextos a que lhes correspondiam, os entrevistados responderam ao questionário - cada um estruturado com seis perguntas fechadas -, conformando um instrumento conciso e breve.

Estas perguntas, de caráter objetivo, foram elaboradas com base em respostas dicotômicas e múltiplas, evitando ambiguidades e equívocos por parte do respondente. Cada pergunta referente às obras analisadas se relacionava com a cena em questão - a título recordativo para o entrevistado -, e com suas opiniões ligadas à narrativa da família homoparental na ficção televisiva de seu país de origem. 
A Família Homoparental na Ficção Televisiva...

\section{RESULTADOS}

Com base nos objetivos anteriormente explicitados, no trajeto teórico-conceitual realizado e nas análises da amostra da pesquisa, destacamos o papel da televisão como espaço de relações dialógicas, enfatizando outro conceito que deve ser recuperado quando se falar em televisão: a pluralidade, que, como argumentou Ferré Pavia (2010), possibilita um conteúdo variado e multitemático, em que a sociedade se vê representada, apesar de sua diversidade. Identificamos, também, características importantes nos perfis dos dois casais homossexuais estudados e a prática narrativa emancipadora de Hospital Central, por meio da família homoparental 1, diferentemente das limitações de aprofundamento do vínculo afetivo-amoroso e das relações paterno-filiais detectadas na família homoparental 2, de Páginas da Vida. Frisamos, ainda, a construção de uma estrutura de pesquisa relevante para a consolidação de uma linha de estudo acadêmica, direcionada à família homoparental na ficção televisiva.

\section{Os Perfis dos Casais Homossexuais e suas Diferenças}

Seguindo a lógica metodológica estabelecida para os atributos morfológicos dos quatro personagens estudados - Maca e Esther (família homoparental 1); Marcelo e Rubinho (família homoparental 2) -, relacionados às suas características físicas e corporais, destacamos a utilização de atores e atrizes de boa imagem e atraentes, o que poderia vir a ser um estereótipo comum na ficção de modo geral. De acordo com a pesquisa, pudemos constatar que os personagens estudados apresentaram, cada um, traços peculiares que os caracterizavam de maneiras distintas. A pediatra Maca era mais reservada e afetuosa; a enfermeira Esther parecia ser mais espontânea e extrovertida; já o dermatologista Rubinho se mostrou equilibrado e tranquilo, e o músico Marcelo era ingênuo e sensível. No entanto, em momentos pontuais das tramas, os perfis chegam a assimilar-se, denotando um contraste próprio do ser humano com seu entorno, sempre privilegiando o profissionalismo, o talento e as amizades de cada casal. Não identificamos nenhum perfil pejorativo ou forçosamente vinculado à orientação sexual dos personagens, revelando que a sexualidade não foi concebida, nas obras, como um fator determinante para a construção da personalidade e da emotividade de cada um.

O tratamento do discurso amoroso referente à família homoparental 1 contou com histórias de fácil identificação com os telespectadores, ain-

DADOS - Revista de Ciências Sociais, Rio de Janeiro, vol. 58, nº 1, 2015 
da que espacialmente limitado por acontecer, na maior parte das vezes, em uma unidade de urgências médicas. A relação amorosa não tradicional, independentemente de sua orientação sexual, teve um tratamento, até certo ponto, aprofundado com beijos e carícias, ainda que de forma dinâmica, já que sabemos da ágil estrutura temporal das histórias que envolviam os sujeitos, pela autonomia de cada capítulo da série. O destaque da relação ocorreu em momentos pontuais: no casamento das duas mulheres, na gravidez por inseminação artificial da pediatra Maca e nos conflitos com a educação do filho.

Já no tocante à família homoparental 2, comprovamos que se tratava de uma relação estável, embora informal, com pouca intimidade e carícias, e cujo único dilema se referia à decisão de lutar na Justiça pela adoção de um filho, o que somente pareceu ser uma escolha definitiva do casal no último capítulo da novela, quando os dois homens, na cama, ainda que sem carinho mútuo, afirmaram que tinham esse direito para completar a família.

Verificamos, aí, um ponto-chave de diferença entre os dois casais: o tratamento das relações paterno-filiais associado a cada casal. O primeiro recebeu o aprofundamento do tema dentro do que coube à narrativa, ambientada num hospital, explorando conflitos relacionados a religião, educação, transgressão de valores tradicionais, como a gravidez de uma das mulheres por meio de inseminação artificial. No que se refere ao segundo casal, a introdução do tema da adoção por casais homossexuais é apresentada como o único link transgressor em relação aos dois homens. O nascimento da filha da empregada doméstica dos rapazes trouxe à tona o debate, já fortalecido pelo incentivo da mãe de um deles para se tornar "avó". Foi, então, o desfecho da indecisão do casal: a certeza de que queriam e que poderiam adotar uma criança.

Na observação empírica da amostra própria, do ponto de vista dos atributos narrativos estabelecidos pela investigação e baseados nas sequências de interesse, quantificamos que, nas duas temporadas, a família homoparental 1 obteve, em média, 60 minutos de presença em tela; já a família homoparental 2 apareceu em pouco mais de 58 minutos, denotando, em nossa opinião, um equilíbrio significativo de representação dos dois universos narrativos estudados, ainda que consideremos que o primeiro casal obteve destaque na trama, dentro da amostra escolhida, diferentemente do segundo casal, que somente começou a ter visibilidade na novela a partir do capítulo 32. Outro ponto de incongruên- 
cia encontrado diz respeito à quantidade de sequências de interesse obtidas para cada casal: 165 para o casal espanhol e 33 para o brasileiro, o que ratifica o protagonismo e a introdução de fios narrativos dos personagens estudados da série espanhola.

\section{O Discurso Integrado de Hospital Central}

O principal ponto em comum entre a série espanhola e a novela brasileira se apresentou na tentativa de romper com o contrato heteronormativo, conceito abordado por Allrath e Gymnich (2005), ainda que interpretemos essa espécie de liberação narrativa em favor da representação das mudanças sociais diante da homossexualidade. Também devemos recordar que, por culpa do desejo da sociedade de diferenciar categoricamente as sexualidades, pressupõe-se à heterossexualidade uma identidade, enquanto à homossexualidade, a introdução da diferença ou da heterogeneidade. Por estas razões, entendemos que se trata de uma afirmação própria do sistema heteronormativo, se considerarmos as convenções narrativas dominantes: casais estáveis, atraentes fisicamente, bem-sucedidos e levando uma vida familiar comportada e aceita pelo seu entorno. Atenuou-se a realidade gay para evitar choques aos telespectadores; uma iniciativa que, a fim de dar mais visibilidade aos homossexuais, não deveria, em nosso ponto de vista, ser menosprezada nem sob esta condição.

De forma geral, as características narrativas da série espanhola, em nossa opinião, fazem desta obra um bom observatório da representação televisiva das novas relações afetivo-amorosas, por oferecer ao telespectador a possibilidade de assistir ao argumento narrativo de um casal homossexual, praticamente com o mesmo tratamento dado aos casais heterossexuais da trama ${ }^{17}$, sem a veia estereotipada que costumava disseminar, de um lado mais suave, o tabu ou o desconhecimento, de outro, nem tanto, a homofobia. A questão paterno-filial merece ser enfatizada em Hospital Central, a partir da perspectiva inovadora no tratamento de temas como a inseminação artificial por uma mulher lésbica, a educação de um filho com duas mães e o questionamento da tradição, como o batizado.

Efetivamente, constatamos nessa amostra que a questão da maternidade entre as duas mulheres poderia ser um problema com a tentativa de batismo do filho, denotando o quão delicado que era para a Igreja Católica aceitar a substituição de um marido por uma esposa. Apesar da in-

DADOS - Revista de Ciências Sociais, Rio de Janeiro, vol. 58, nº 1, 2015 
dignação pelo dilema em batizar o bebê, Maca aceitou a proposta de Esther de educar bem o filho, e de que esperassem que ele crescesse para decidir, por si mesmo, se queria submeter-se a este ritual católico. Novamente, um elemento transgressor se fez presente à trama, indicando a ruptura de uma convenção, e a sugestão de que a educação dos filhos desta nova família deveria estar baseada na liberdade e no respeito.

Como tendência geral, apontamos uma visibilidade crescente da identidade homossexual como consequência direta dos ganhos obtidos pelo movimento homossexual - tendências nas televisões dos dois países. Reforçamos que nossas considerações do contexto foram imprescindíveis para poder estabelecer uma articulação entre a metodologia empregada e seus distintos níveis, até a conclusão de que as realidades e os contextos do mundo da televisão e do real se tocam e se entrelaçam em um grau que ainda exige mais determinação.

\section{O Discurso Moderado de Páginas da Vida}

No contexto brasileiro, o que pudemos destacar foi a timidez no tratamento desses vínculos, no caso dos dois homens, em contraste com as experiências narrativas em relação à família homoparental 1, que tinham filhos e conflitos ligados à educação. A família homoparental 2 teve parte de seus argumentos narrativos direcionados à construção do desejo de adotar uma criança, culminando, no último episódio, com a certeza de que criariam a filha de sua empregada doméstica e efetivariam uma adoção legal, ainda que isso, àquele momento, significasse uma batalha judicial. A partir dos capítulos estudados, podemos afirmar, também, que as duas obras de ficção apresentaram uma vocação pedagógica e um compromisso moral em que se verificou uma dedicação profissional tamanha a ponto de chegar à implicação pessoal. Outro dado importante se refere à capacidade inovadora no formato de Páginas da Vida, que incluiu, no final de cada capítulo, depoimentos de pessoas anônimas, narrando um acontecimento marcante de suas vidas, relacionando, desta forma, as participações aos temas abordados nos episódios.

Nesse sentido, esses dados podem ser ainda mais relevantes quando um argumento narrativo delimita que a orientação sexual de seus personagens não recebe atenção além daquela que merece, demarcando o espaço que separa o personagem profissional e o personagem pessoal. 
No entanto, apesar do esforço de normalização da família homoparental na ficção televisiva dos dois países, reconhecemos que, do ponto de vista comparativo, há outras congruências interessantes que marcam a posição dos dois casais analisados, uma vez observadas justificativas de roteiro para explicar e convencer a audiência. Tomamos, como exemplo, a necessidade de inserir à trama as opiniões dos pais dos personagens Maca e Esther, ratificando que a aceitação paterna da homossexualidade dos filhos é um tema que não se pode evitar debater. É mais um traço, em nossa opinião, da tentativa de normalização da experiência homossexual na TV. Neste caso, a resistência dos pais - princípio notadamente expressivo quando é desafiado o pilar em que se alicerça a família heterossexual -, foi tratada como conflito maior, com um desenlace em clima de menos intolerância e, por final, de aceitação. $\mathrm{O}$ mesmo aconteceu em Páginas da Vida, já que os pais de Rubinho foram mencionados na trama como resistentes à orientação sexual do filho, $\mathrm{o}$ que, por isso, obrigava o médico a evitar criar pontos de conflito, omitindo da família progressões ligadas ao seu namoro com Marcelo.

Verificamos, portanto, que ambas as obras fizeram seu particular esforço para romper com o contrato heteronormativo. Trata-se de uma normalização ratificada em propósitos sutis, como, por exemplo, mostrar que um personagem, até então, de orientação heterossexual, pode tornar-se homossexual sem que, para isso, necessite revolucionar sua trajetória de vida. Referimo-nos ao caso do personagem Esther, que se assume homossexual depois de apaixonar-se por Maca. Referência alguma, nesse sentido, registramos com o casal brasileiro.

Entendemos que têm mais fundamento na prática narrativa estudada elementos transgressores como a autonomia pessoal, a liberdade e a igualdade profissional e sexual de personagens masculinos e femininos, e a consideração narrativa de que uma união amorosa pode não ser uma opção vitalícia. Cabe ressaltar, ainda, a relevância da atitude de Hospital Central em oferecer ao imaginário coletivo a certeza da legitimidade dos vínculos amorosos, da solidez dos laços que se estabelecem, indiferentemente de orientação sexual, e dos novos modelos familiares, que não excluem o aspecto idílico das relações paterno-filiais. No caso brasileiro, podemos discorrer sobre outra certeza: a de que os novos vínculos amorosos que emergem ainda precisam de aceitação social para que se proliferem e deixem de ocupar a margem da sociedade e a borda da ficção. 


\section{A ANÁLISE VIRTUAL-COMPARATIVA}

As cenas de Hospital Central e Páginas da Vida disponibilizadas na nossa página na web foram consideradas conhecidas pela maioria dos entrevistados em cada grupo; foram tidas como polêmicas, de acordo com o coletivo brasileiro, diferentemente do que ponderou o coletivo espanhol; e, por quase unanimidade, os dois grupos afirmaram que faltava, nas televisões de seus países, uma abordagem mais abrangente das relações paterno-filiais de casais homossexuais.

Vale destacar que o grupo que reconhece que faltam intimidade e afetividade na representação do casal homossexual 2 (Rubinho/Marcelo), é o mesmo que rechaça a necessidade de prudência na exibição de relações afetivo-amorosas como essa, o que poderíamos deduzir que se trata de uma coerência opinativa; afinal, uma cena, notadamente carente de demonstração afetiva, já denota moderação no seu tratamento.

Outro aspecto que merece ser compartilhado, no que se refere ao grupo brasileiro, foi a crença de $90 \%$ dos entrevistados de que a televisão no Brasil será capaz de narrar, de maneira aprofundada, na ficção, casos de famílias homoparentais.

Esse otimismo também é verificado no caso espanhol, já que $83 \%$ dos informantes avaliaram a televisão de seu país como um potencial modelo para outras televisões no âmbito do tratamento de novas relações afetivo-amorosas, sendo um espelho da sociedade em que vivem. Reiteradamente, $71 \%$ afirmaram que a televisão da Espanha acompanha as mudanças verificadas no tecido social, o que ratificaria uma de nossas hipóteses, já que com esta característica, a ficção deste país tende a revelar novas representações familiares.

\section{Grupo na Espanha - 52 participantes}

Ao entrar no nosso site, na área reservada ao coletivo espanhol, cada entrevistado era convidado a assistir à cena de Hospital Central (Seq. 151/cap.13/ 01:08:12), ali publicada antes de proceder à leitura e à escolha das respostas, marcando sí ou no como opções oferecidas. Chamou-nos a atenção o fato de haver uma pequena diferença entre os entrevistados que conheciam e que desconheciam a cena de Hospital Central, disponibilizada em nosso site. Do total destes, 54\% disseram ter assistido ou ouvido falar da sequência que evidencia o casamento 
entre as duas mulheres. E a mesma cena, para 43 dos informantes, conformando $83 \%$ do universo, não foi considerada controversa na sociedade. Quando perguntados se relações homoafetivas, como a exibida no site, deveriam receber um tratamento moderado na ficção espanhola, quase todos (98\%) responderam que "Não".

A maioria, nesse caso formada por $71 \%$ dos entrevistados, confirmou que a televisão espanhola tem acompanhado as mudanças sociais no que se referia à orientação homossexual. Não obstante, um elevado percentual de informantes (98\%) demonstrou não ter dúvidas de que era necessária uma abordagem maior no tocante às relações paterno-filiais entre casais homossexuais.

Mesmo assim, 43 respostas (83\%) ratificaram que a narrativa de ficção televisiva da Espanha poderia servir de modelo a outras emissoras no que concerne ao fato de retratar ou recriar a vida real na tela.

\section{Grupo no Brasil - 52 participantes}

Quando perguntados se já tinham ouvido falar ou se haviam assistido à cena em que o casal homossexual de Páginas da Vida (Seq. 228/ Cap. 203/00:19:04) está em sua cama, despertando juntos, metade dos brasileiros entrevistados respondeu que sim. Do total, 28 pessoas ( $54 \%$ dos entrevistados) disseram que esta cena exibia pouca intimidade entre um casal homossexual, diferentemente do que se costuma ver em uma cena de trato íntimo entre um casal heterossexual na televisão.

Para uma maioria apertada (28 respostas), a cena, mesmo exibida em 2007, ainda parece ser polêmica nos dias atuais, já que 54\% acreditavam que as imagens seriam capazes de gerar controvérsia na sociedade brasileira. Apenas 15\% dos entrevistados consideraram que as relações homoafetivas como esta de Páginas da Vida deveriam ser tratadas com moderação na ficção televisiva do Brasil, enquanto $96 \%$ não tiveram dúvidas de que as relações homoparentais mereciam maior abordagem nas narrativas de ficção.

Em relação à pergunta que sondava a opinião sobre a possibilidade de a ficção brasileira narrar, de forma aprofundada, casos de famílias homoparentais, $90 \%$ mostraram uma posição otimista. Cinco pessoas discordaram. 


\section{CONCLUSÃO - O NOVO DIÁLOGO ENTRE DESEJO E TRADIÇÃO NA FICÇÃO}

Relações construídas na ausência de uma lei consensual, ainda que inevitavelmente inspiradas na tradicionalização do vínculo amoroso, e que possuem uma subjetividade e intimidade orientadas conforme o próprio desejo, com um código ainda longe de ser estandardizado: entendemos que seja esta a tendência afetivo-amorosa que se aponta nas duas produções de ficção aqui estudadas.

Reconhecemos, ainda, que, ao estudar a família homoparental, assim como a heterossexual, não se pode esquecer o cultivo de uma interioridade que dê conteúdo às relações, de cônjuge ou não, ou mesmo em um romance passageiro. Ao nos centrarmos excessivamente no casamento pode fazer com que nos esqueçamos que, certamente, como estrutura, este esteja supervalorizado. Preferimos nos valer do conceito de "família plástica", concebido por Sáez (2008), que reitera o que verificamos no trajeto teórico desta investigação: as relações e os vínculos, neste contexto de diversidade formal e liberdade individual, ganham em sinceridade, mas, também, em fragilidade. Investigar as novas relações afetivo-amorosas nos obriga a ter esse conceito sempre em mente, a fim de considerar o caráter dialético e mutacional da família, sobretudo.

No momento em que desenvolvemos o presente estudo, os contextos legal e televisivo do Brasil e da Espanha revelaram contrastes substanciais entre os dois países. Mesmo assim, não houve ânimo em adotar uma postura colonizadora ou Europa-centrista. Os resultados desfavoráveis ao âmbito brasileiro se devem à ausência, naquele período estudado, de modelos familiares homoafetivos consistentes, apesar da vasta representação homossexual na televisão do Brasil.

Do ponto de vista do meio de comunicação estudado, uma sugestão deixada por esta linha de investigação é a de que este possa servir de antecedente ao desenho de iniciativas culturais de produção das cadeias televisivas, sintonizadas ao contexto da contemporaneidade, de modo a revitalizar o vínculo social como função de serviço público da televisão, transmissora de valores. Neste sentido, entendemos que, como intelectuais, devemos exercer nossa capacidade crítica diante dos efeitos de dominação de ideologias e instituições, porém, ao mesmo tempo, devemos insistir no resgate da capacidade de gerar marcos de referência que nos permitam interpretar o presente e articular 
vontades em prol de projetos comuns, em que prevaleçam a igualdade de tratamentos narrativos dos personagens, sem influência da sexualidade, para que, assim, possamos conquistar, verdadeiramente, futuro mais justo e sem discriminação.

Daí vem nossa proposta máxima, a de que o Brasil possui identidade própria para tratar, mais abertamente, de um tema como a família homoparental, igualmente como observamos na Espanha. O beijo entre dois homens em uma telenovela brasileira, em janeiro de 2014, não foi um simples beijo, ainda que considerado por muitos como pouco íntimo e inspirador do real, diferentemente do primeiro beijo lésbico da televisão brasileira. Longe de avaliar a qualidade do beijo consagrado, reconhecemos que seu caráter revolucionário é irrefutável. Promove questionamentos, induz a uma normalização, incita à tolerância. Esta tendência dramática representa uma tendência social. E vice-versa.

Não se trata, porém, de um trajeto linear fácil. Tanto na Europa quanto no Brasil, a resposta social aos modelos familiares gays e lésbicos mantém a ficção televisiva em um estado de certa tensão, ainda que seja um espaço de liberdade individual que será cada vez mais normalizado. Cabe destacar que, dentro desta normalização, homens e mulheres homossexuais ainda não são igualmente tratados, o que faz com que a ficção televisiva tenha outro campo de trabalho em prol da igualdade deste coletivo, no contexto de suas representações familiares.

A prática narrativa e as especificidades verificadas em Hospital Central constituem uma base para analisar a mudança social inserida na ficção, concretamente no conteúdo narrativo sobre a família homoparental na televisão, também presente no contexto brasileiro. E ratificam o potencial investigativo de um inovador campo acadêmico a que começamos a dar vida: a família homoparental na ficção televisiva. Um estudo como este traz a reflexão acerca dos novos valores nas relações afetivo-amorosas que emergem na contemporaneidade e debate, assim, sobre a disseminação desses valores e seus modelos nas narrativas televisivas, em direção a uma sociedade diversificada, mas democrática (Mesquita, 2012). Conforme identificamos na pesquisa, especialmente a partir dos questionários virtuais de coletivos homossexuais do Brasil e da Espanha, a falta de protagonismo da família homoparental e suas especificidades, tanto na televisão, de forma geral, quanto no universo acadêmico, no nosso ponto de vista, transformam o tema em 
um segredo por revelar, uma verdade a compartilhar, e que, por isso, motivou esta pesquisa, podendo, com sorte, motivar outras.

Com isso, a expectativa aqui é a de que o delineamento de um campo de investigação tão instigante quanto inovador possa servir de antecedente ao desenho de iniciativas culturais de produção das cadeias televisivas, sintonizadas ao contexto da contemporaneidade, a fim de revitalizar o vínculo social como função primordial da televisão contemporânea.

(Recebido para publicação em novembro de 2012)

(Reapresentado em fevereiro de 2014)

(Aprovado para publicação em agosto de 2014) 
A Família Homoparental na Ficção Televisiva...

\section{NOTAS}

1. Este conceito de família homoafetiva é abordado com lucidez por Dias (2007:9): "Ainda que, quase intuitivamente, se conceitue a família como uma relação interpessoal entre um homem e uma mulher tendo por base o afeto, necessário reconhecer que há relacionamentos que, mesmo sem a diversidade de sexos, são cunhados também por um elo de afetividade".

2. A série Hospital Central foi finalizada com a $20^{\mathrm{a}}$ temporada, em 2012, depois de 12 anos de exibição. Disponível em <http:/ / www.telecinco.es/hospitalcentral > . Acesso em $15 / 2 / 2014$.

3. A novela, exibida entre os anos 2006-2007, contou com 203 capítulos e ficou conhecida por promover merchandising social. Assim, a emissora Rede Globo se referia ao serviço oferecido pela obra como de abordagem e sensibilização de assuntos polêmicos na sociedade brasileira. Mais informações em <http://memoriaglobo.globo.com/Memoriaglobo/0,27723,GYN0-5273-245851,00.html>. Acesso em 9/4/2012.

4. Aqui, a autora rememora uma das várias qualificações pejorativas atribuídas aos homossexuais ao longo dos anos. Também, elenca outras como sodomitas, perversos ou doentes mentais. Em momento algum fica subentendido que se trata de juízo de valor da autora.

5. As obras de Alfred Kinsey et al. mencionadas por Giddens são: Sexual Behaviour in the Human Male (Filadélfia, Saunders, 1948) e Sexual Behaviour in the Human Female (Filadélfia, Saunders, 1953).

6. Segundo a autora, este conceito contemplaria um conjunto de áreas presentes na vida cotidiana das pessoas, incluindo autonomia do corpo, usos do espaço, as emoções, a moral e a sexualidade.

7. Frisamos que o IBGE é o maior provedor de dados e informações estatísticas do Brasil. Disponível em <http:/ /www.ibge.gov.br/home/>. Acesso em 11/9/2013.

8. De acordo com a reportagem, a cada dois dias um homossexual era assassinado no Brasil. Disponível em <http://gazetaweb.globo.com/v2/noticias/texto_completo.php?c=198846>. Acesso em 11/9/2013.

9. Outros dados da pesquisa disponíveis em $<\mathrm{http}$ ://agenciabrasil.ebc.com.br/noticia/2011-07-28/maioria-dos-brasileiros-e-contra-uniao-estavel-e-adocao-por-casais -homossexuais $>$. Acesso em 11/9/2013.

10. Disponível em <http://www.ine.es/>. Acesso em 11/9/2013.

11. Outras informações disponíveis em < http://www.sbt.com.br/amorerevolucao/> e <http://televisao.uol.com.br/ultimas-noticias/multi/2011/05/13/ 04028C9C3268C8A11326.jhtm?sbt-exibe-o-primeiro-beijo-lsbico-da-tv-brasileira-04028C9C3268C8A11326>. Acesso em 17/1/2014.

12. Na reta final da novela, foi oferecida à audiência da Internet a possibilidade de decidir o futuro da relação amorosa entre as duas mulheres. Com mais de 50 mil votos, os internautas escolheram que a advogada Marcela deveria terminar a novela com Marina. Mais informações em <http://www.sbt.com.br/amorerevolucao/fiquepordentro/?c=1855>. Acesso em 17/1/2014.

DADOS - Revista de Ciências Sociais, Rio de Janeiro, vol. 58, nº 1, 2015 


\section{Aline Martins Mesquita e Carme Ferré Pavia}

13. A cena do beijo entre os dois homens, exibida no dia 31 de janeiro de 2014, teve grande repercussão, inclusive fora do país. Disponível em <http://brasil.elpais. $\mathrm{com} / \mathrm{brasil} / 2014 / 02 / 01 /$ sociedad/1391219346_869675.html>. Acesso em $8 / 2 / 2014$.

14. Mais informações sobre o GGB disponíveis em <http://www.ggb.org.br>. Acesso em $11 / 4 / 2013$

15. A entidade FLG foi criada em 2003, na Catalunha, com o objetivo de lutar pelos direitos e deveres das famílias homoparentais. Segundo o site da associação, atualmente 300 famílias, entre sócios e simpatizantes, fazem parte da FLG, que conta com delegações em toda a Espanha. Mais informações disponíveis em <http://www.familieslg.org/familieslgtb/>. Acesso em 11/4/2013.

16. O ambiente virtual elaborado para o trabalho ficou no ar durante seis meses e foi desabilitado em 2012

17. Em nossa dissertação de mestrado (Universitat Autònoma de Barcelona, 2009), comprovamos, através de uma análise textual e de atributos entre dois casais de Hospital Central - um casal homossexual e outro heterossexual - que a série de ficção apresentava os dois relacionamentos com equilíbrio no tocante à presença na tela e ao fio narrativo desenvolvido na amostra estudada. 
A Família Homoparental na Ficção Televisiva...

\section{REFERÊNCIAS BIBLIOGRÁFICAS}

ALLRATH, Gaby e GYMNICH, Marion. (2005), Narrative Strategies in Television Series. New York, Palgrave Macmillan.

BAL, Mieke. (1990), Teoría de la Narrativa. Una Introducción a la Narratología. Madri, Ed. Cátedra.

BAUMAN, Zigmunt. (2007), Amor Líquido. Acerca de la Fragilidad de los Vínculos Humanos. Madri, Fondo de Cultura Económica de Espanha.

BELGRANO RAWSON, Milagros. (2012), “Ley de Matrimonio Igualitario y Aborto en Argentina: Notas sobre una Revolución Incompleta". Revista Estudos Feministas, vol. 20, no 1 , pp. 173-188.

CASETTI, Francesco e DI CHIO, Frederico. (1999), Análisis de la Televisión. Barcelona, Paidós.

CASTELLS, Manuel. (1999), La Era de la Información - Vol 2. El Poder de la Identidad. Madri, Alianza Editora.

CEBALLOS FERNÁNDEZ, Marta. (2012), "Ser Madres y Padres en Familias Homoparentales: Análisis del Discurso de sus Percepciones sobre la Educación de sus Hijos e Hijas". Ensayos, Revista de la Facultad de Educación de Albacete, no 27. Disponível em <http:/ / www.revista.uclm.es/index.php/ensayos>. Acesso em 12/7/2013.

DIAS, Maria Berenice. (2007), "Homoafetividade e o Direito à Diferença". Disponível em <http: / / www.blogdolfg.com.br.23 agosto>. Acesso em 20/2/2014.

FERRÉ PAVIA, Carme. (2010), "Pluralisme i Mitjans de Comunicació, per un Pacte Necessari". La Catalunya Plural. Fundació CatDem. Disponível em <http: / /www.catdem.org/cat/downloads2/la-catalunya-plural.pdf>. Acesso em 11/4/2012.

FLAQUER, Lluís. (1991), ¿Hogares sin Familia o Familias sin Hogar? Un Análisis Sociológico de las Familias de Hecho en España". Papers, Revista de Sociologia, no 36, pp. 57-78.

FONSECA, Claudia. (2008), “Homoparentalidade: Novas Luzes sobre o Parentesco". Revista Estudos Feministas, vol. 16, no 3, pp. 769-783.

FOUCAULT, Michel. (1984), História da Sexualidade 2. O Uso dos Prazeres. (9a ed.). Rio de Janeiro, Graal.

FOUTS, Gregory e INCH, Rebecca. (2005), “Homosexuality in TV Situation Comedies. Characters and Verbal Comments". Journal of Homosexuality, vol. 49, no 1, pp. 35-45.

GALÁN, Elena e HERRERO, Begoña. (2011), El Guion de Ficción en Televisión. Madrid, Síntesis.

GARCÍA DE CASTRO, Mario. (2002), La Ficción Televisiva Popular. Una Evolución de las Series de Televisión en España. Barcelona, Gedisa Editorial.

GIDDENS, Anthony. (2004), La Transformación de la Intimidad. Sexualidad, Amor y Erotismo en las Sociedades Modernas. (4a ed.). Madrid, Cátedra.

IGARTUA, Juan José et al. (1998), “Indicadores Culturales y Construcción de Estereotipo en Filmes de Ficción”. Fundación Infancia y Aprendizaje. Madrid, Comunicación y Cultura.

DADOS - Revista de Ciências Sociais, Rio de Janeiro, vol. 58, nº 1, 2015 


\section{Aline Martins Mesquita e Carme Ferré Pavia}

IRAEGUI, Ana e QUEVEDO, María Paz. (2002), “Aproximación Psicolingüística al Estudio de la Personalidad en Español: Una Propuesta Taxonómica". Iberpsicología, vol. 7, no 1, pp. 1-3.

JOYCE, Samantha Nogueira. (2013), “A Kiss Is (Not) Just a Kiss: Heterodeterminism, Homosexuality and TV Globo Telenovelas". International Journal of Communication, no 7, pp. 48-66.

LA PASTINA, Antonio C.; REGO, Cacilda M. e STRAUBHAAR, Joseph D. (2004), “La Centralidad de las Telenovelas en la Vida Cotidiana de América Latina: Tendencias Pasadas, Conocimiento Actual e Investigación por Venir". Global Media Journal, vol. 1, no1. Disponível em <http:/ / www.redalyc.org/articulo.oa?id=68710109>. Acesso em $14 / 5 / 2014$.

MARTÍN-BARBERO, Jesús. (2002), “La Educación desde la Comunicación”. Eduteka Tecnologías de Información y Comunicaciones para Enseñanza Básica y Media, Editorial Norma. Disponível em <http://www.eduteka.org/pdfdir/SaberNarrar.pdf>. Acesso em 19/2/2014.

MEDEIROS, Camila Pinheiro. (2006), “Uma Família de Mulheres: Ensaio Etnográfico sobre Homoparentalidade na Periferia de São Paulo". Revista Estudos Feministas, vol. 14 , no 2, pp. 535-547.

MESQUITA, Aline Martins. (2009), A Família Homossexual nas Séries de Ficção: A Prática Narrativa da Série Espanhola Hospital Central como Relato das Novas Representações Afetivo-Amorosas. Dissertação de mestrado, Universitat Autònoma de Barcelona, Bellaterra.

. (2012), A Família Homoparental na Ficção Televisiva: As Práticas Narrativas do Brasil e da Espanha como Relatos das Novas Representações Afetivo-Amorosas. Tese de doutorado, Universitat Autònoma de Barcelona, Bellaterra.

MIRA, Alberto. (2007), De Sodoma a Chueca. Una Historia Cultural de la Homosexualidad en España en el Siglo XX. (2a ed.). Madrid, Editorial Egales S.A.

NUNAN, Adriana. (2003), Homossexualidade: Do Preconceito aos Padrões de Consumo. Rio de Janeiro, Editora Caravansarai.

PERELSON, Simone. (2006), “A Parentalidade Homossexual: Uma Exposição do Debate Psicanalítico no Cenário Francês Atual”. Revista Estudos Feministas, vol. 14, no 3, pp. 709-730.

PÉREZ CÁNOVAS, Nicolás. (1996), Homosexualidad. Homosexuales y Uniones Homosexuales en el Derecho Español. Granada, Editorial Comares.

REYES, Hernán. (2007), “Las Otras Sexualidades. Visibilizaciones, Resistencias y Disidencias". América Latina en Movimiento, no 420, pp. 10-13.

ROBALDO, Marcelo. (2011), “La Homoparentalidad en la Deconstrucción y Reconstrucción de Familia. Aportes para la Discusión”. Revista Punto Género, no1, pp. 171-183.

ROUDINESCO, Elisabeth. (2003), A Família em Desordem. Rio de Janeiro, Jorge Zahar.

SÁEZ, Lluís. (2008), Família i Valors: La Institució Familiar en Temps de Canvi. Barcelona, Fundació Lluís Carulla, ESADE (Colõlecció Observatori dels Valors, no 7). 
A Família Homoparental na Ficção Televisiva...

SÁEZ MATEU, Ferran. (2008), Mitjans de Comunicació i Valors: Què Volem que Siguin els Mitjans? Barcelona, Fundació Lluís Carulla, ESADE (Collecció Observatori dels Valors, no 5).

SAMPIERI HERNÁNDEZ, Roberto; COLLADO FERNÁNDEZ, Carlos e LUCIO BAPTISTA, Pilar. (2003), Metodología de la Investigación. México, McGraw Hill.

SANTOS, José A. Figueiredo. (2011), “Desigualdade Racial de Saúde e Contexto de Classe no Brasil". DADOS - Revista de Ciências Sociais, vol. 54, no 1, pp. 5-40.

SERBIA, José María. (2007), “Diseño, Muestreo y Análisis en la Investigación Cualitativa". Hologramática, Año IV, no 7. Disponível em <www.cienciared.com.ar/ ra/usr/3/206/n7_vol3pp123_146.pdf >. Acesso em 10/4/2012.

VILLAAMIL, Fernando. (2004), La Transformación de la Identidad Gay en España. Madrid, Catarata. 
RESUMO

A Família Homoparental na Ficção Televisiva: As Práticas Narrativas do Brasil e da Espanha como Relatos das Novas Representações

Afetivo-Amorosas

Este artigo analisa o tratamento da família homoparental nas televisões do Brasil e Espanha. Destaca-se a interdisciplinaridade entre família, sociedade e ficção através de um recorte das obras Hospital Central (Telecinco, 2000-2012) e Páginas da Vida (Rede Globo, 2006-2007), com análise, em ambos os casos, de atributos de uma família homoparental de cada, e análise textual de conteúdo. Foi aplicada também técnica de suporte metodológico por meio de questionários com coletivos homossexuais dos dois países, a fim de obter dados sobre consumo e percepção. Os resultados encontrados ratificam a representação articulada entre desejo e tradição nas relações, e a tendência das obras de evitar o estereótipo homossexual. Observa-se a prática narrativa atrevida da série espanhola e o tratamento aprofundado de um casal formado por duas mulheres, à diferença da novela brasileira, em que o amor entre dois homens apresentou restrição na abordagem afetivo-amorosa e paterno-filial. Finalmente, detectam-se elementos para uma nova linha de estudo internacional: a família homoparental na televisão.

Palavras-chave: família gay e lésbica; relações paterno-filiais; televisão e mudança social; prática narrativa em televisão; homossexualidade e ficção

\section{ABSTRACT}

The Homo-parental Family in TV Fiction: The Narrative Practices of Brazil and Spain in the Representation of Relationships of Love-Affection

This article analyzes the treatment of the homo-parental family in the Brazilian and Spanish television. It highlights the cross-disciplinary aspects of family, society and fiction through a sample of programs - Hospital Central (Telecinco, 2000-2012) and Páginas da Vida (Rede Globo, 2006-2007) - analyzing, in both cases, how homo-parental families were portrayed and text-analysis of content. A methodological support technique was also applied through a survey with homosexual collectives in both countries in order to obtain consumption and perceptions related data. The findings ratify the representation articulated between desire and tradition in relationships, and the way these programs tend to avoid homosexual stereotypes. It was possible to notice the daring narrative in the Spanish series, along with a non-superficial approach of the couple formed by two women, while in the Brazil, the portrayal of the love between two men displayed limitations in its approach to the dimensions of affection-love and paternal-filial relations. Lastly, elements for a new line of cross-boundary investigation are outlined: the homo-parental family on television.

Keywords: gay and lesbian families; paternal-filial relationships; television and social change; narrative practices on television; homosexuality and fiction 
RÉSUMÉ

La Famille Homoparentale dans la Fiction Télévisée: Les Pratiques

Narratives du Brésil et d'Espagne comme Expressions des Nouvelles Représentations Affectivo-amoureuses

Cet article analyse le traitement donné à la famille homoparentale par les télévisions du Brésil et d'Espagne. Y est mise en évidence l'interdisciplinarité entre famille, société et fiction dans les œuvres Hospital Central (Telecinco, 2000-2012) et Páginas da Vida (Rede Globo, 2006-2007). Dans les deux cas, les attributs d'une famille homoparentale ont été étudiés et une analyse textuelle de contenu a été menée. La méthodologie adoptée a consisté à proposer des questionnaires à des collectifs homosexuels des deux pays dans le but d'obtenir des données relatives à la consommation et perception. Les résultats obtenus ont confirmé une représentation articulée entre désir et tradition au sein des relations, ainsi que la tendance des œuvres en question à éviter le stéréotype homosexuel. On a observé la pratique narrative audacieuse de la série espagnole et le traitement approfondi donné à un couple formé par deux femmes, contrairement au feuilleton brésilien, où l'approche affectivo-amoureuse et paterno-filiale de l'amour entre deux hommes a été beaucoup plus timide. Finalement, nous avons mis en lumière des éléments permettant d'alimenter une nouvelle ligne de recherches internationales: la famille homoparentale à la télévision.

Mots-clés: famille gay et lesbienne; relations paterno-filiales; télévision et changement social; pratique narrative télévisuelle; homosexualité et fiction

\section{RESUMEN}

La Familia Homoparental en la Ficción Televisiva: Las Prácticas Narrativas de Brasil y España como Relatos de Nuevas Representaciones Afectivo-Amorosas

Este artículo analiza el tratamiento de la familia homoparental en las televisiones de Brasil y España en su contexto social. Subrayase la interdisciplinaridad entre familia, sociedad y ficción a través de una muestra de las obras Hospital Central (Telecinco: 2000-2012) y Páginas da Vida (Globo: 2006-2007), con análisis de atributos de una familia homoparental de cada obra y análisis textual de contenido. Fue aplicada, también, una técnica complementaria por medio de cuestionarios con colectivos homosexuales de los dos países con el objetivo de obtener datos sobre consumo y percepción. Los resultados confirman la representación articulada entre deseo y tradición en las relaciones bien como la tendencia de las obras en evitar el estereotipo homosexual. Se observa la práctica narrativa más atrevida de la serie española y el tratamiento profundizado de una pareja homosexual formada por dos mujeres, a diferencia de la telenovela brasileña, donde el amor entre dos hombres presentó restricciones en el abordaje afectivo-amoroso y paterno-filial. Finalmente, se abren vías para un nuevo campo de estudio internacional: la familia homoparental en la televisión.

Palabras-clave: familia gay y lesbiana; relaciones paterno-filiales; televisión y cambio social; práctica narrativa en televisión; homosexualidad y ficción

DADOS - Revista de Ciências Sociais, Rio de Janeiro, vol. 58, nº 1, 2015 